\title{
Suitability of a coupled hydrodynamic water quality model to predict changes in water quality from altered meteorological boundary conditions
}

\author{
$\underline{\text { Leon van der Linden }}^{\text {a }}$, Robert I. Daly ${ }^{\text {a }}$ and Mike D. Burch ${ }^{\text {a }}$ \\ ${ }^{a}$ South Australian Water Corporation, Adelaide, SA 5000 \\ Email: leon.vanderlinden@sawater.com.au
}

\begin{abstract}
The application of downscaled climate scenarios can be used to inform management decisions on investment in water treatment infrastructure or alternative water sources. Appropriate models of the system components potentially impacted by climate change such as catchments, rivers, lakes and reservoirs are required. The sensitivity of the coupled hydrodynamic water quality model ELCOM-CAEDYM to climate drivers was investigated to determine its suitability for evaluating climate change impacts and to evaluate the most important climatic drivers.

A case study application of the model to Happy Valley Reservoir was used in the investigation (Romero et al. 2005). The hydrodynamic model was validated against field measurements without calibration. The ecological model was set up using values derived from literature sources and measurements made at other reservoirs. Manual calibration of some parameters was performed, however, performance metrics were not provided by Romero et al. (2005).

A series of simulations were run with altered boundary condition inputs for the reservoir. Air and inflowing water temperature (TEMP), wind speed (WIND) and reservoir inflow and outflow (FLOW) were altered to investigate the sensitivity of these key drivers over relevant domains. The simulated water quality variables responded in the broadly expected manner to the altered boundary conditions; sensitivity of the simulated cyanobacteria population to increases in temperature was similar to published values. This study demonstrated that ELCOM-CAEDYM is sensitive to climate drivers and suitable for use in climate impact studies. It further highlighted the important factors in determining phytoplankton growth and that any changes in inflowing water quality will be of major importance to the dynamics of raw water quality.
\end{abstract}

Keywords: Water quality; Sensitivity analysis; ELCOM-CAEDYM 
Leon van der Linden et al., Suitability of a coupled hydrodynamic water quality model to predict changes in water quality from altered meteorological boundary conditions

\section{INTRODUCTION}

The Goyder Water Research Institute project C.1.1 was initiated to fill a gap in the current understanding of the potential impacts of climate change on South Australia. The project seeks to understand climate drivers, downscale global circulation (GCM) model projections of future climate and develop a suite of model applications for the evaluation of climate change impacts on society. Current global circulation model (GCM) projections suggest Australian average temperatures will increase by 1.0 to 5.0 degrees by 2070 (compared to 1980-1999), there will be decreases in rainfall over southern Australia and there will be an increase in the number of hot days and warm nights (CSIRO 2012). Decreases in winter and autumn wind speed and increases in spring and winter downward solar radiation are also projected, but these projections are subject to large uncertainties (CSIRO 2007). Recent efforts to downscale GCM outputs to the catchment scale have identified the potential for reduced catchment yields as the result of reduced precipitation, changes in rainfall seasonality and increased temperatures (Heneker \& Cresswell 2010; Charles et al. 2008; Green et al. 2011). Besides issues of water quantity, there are potential impacts of climate change on water quality (Whitehead et al. 2009; Delpla et al. 2009). Reservoirs play a major role in determining the water quality within a given water supply system, as they act as both barriers to (e.g. pathogens) and producers of (e.g. cyanobacteria [toxins, tastes and odours], iron and manganese) water quality hazards (Brookes et al. 2008). Reservoirs integrate the prevailing hydrology, meteorology, biology and biogeochemistry and the resulting quantity and quality of water is a valuable resource that requires sound management to ensure the utility and sustainability of the source water; water quality models are a tool to this end.

The potential impacts of climate change on water quality has been evaluated using integrated modelling schemes which include water quality models (Arheimer et al., 2005; Mimikou et al., 2000; Saloranta et al., 2009; Thorne \& Fenner, 2008). Such schemes use a combination of catchment and lake/reservoir models that use meteorological boundary conditions as inputs. The meteorological conditions are altered to represent projected future climate and the resulting simulations are taken to represent the potential impacts of those changed climatic conditions. Too few of these studies have been performed to make generalisations about the potential impacts; both positive and negative influences have been identified. A further issue is that the differences in the model structures and methodologies applied by different researchers makes the separate studies difficult to compare directly. There are many sources of uncertainty within such a modelling scheme, including the choice of GCM, emissions scenario, downscaling methodology, the selection of and rigour of application of the hydrological, constituent and lake/reservoir water quality models. Therefore, each step in the modelling scheme needs to be thoroughly evaluated to ensure the results can be useful.

It is therefore appropriate to test the sensitivity of the proposed reservoir water quality model to changes in the environmental variables expected to change in the future. Formalising our understanding of the way that water quality variables respond to climate related model inputs is fundamentally important to understanding the outputs we generate from models (Elliott 2011). If we plan to use these models to project the impacts of downscaled climate scenarios then it is important that we understand the water quality models sensitivity to the boundary conditions that we are 'forcing' it with. Water quality models vary in their data input requirements and often contain options for the sub-model structures they contain, making it difficult to assume that they will be equally sensitive in any given application. Responses of chemical and biological processes to the changes in physical state generated by changes in meteorological inputs are dynamic and interactive and therefore difficult to resolve without resolving individual sensitivities in an explicit analysis.

Therefore, towards the development of a robust integrated modelling scheme, the sensitivity of the ELCOMCAEDYM model (Hodges \& Dallimore 2007; M Hipsey et al. 2006) to changes in meteorological boundary conditions was analysed. A previous application of the model to Happy Valley Reservoir (HVR) was used in conjunction with environmental forcings that represented incremental changes in flow, air and water temperature, and wind speed. Responses in water quality variables of primary concern were cyanobacteria and soluble metals; further consideration was given to water temperature and water column stratification.

\section{METHODS}

\subsection{Happy Valley Reservoir}

Happy Valley Reservoir is an off stream reservoir that supplies source water to South Australia's largest water treatment plant. As HVR is isolated from its natural catchment it is supplied with water from the Onkaparinga River system via an aqueduct from Clarendon Weir, which is in turn supplied from the much larger Mount Bold Reservoir. Mount Bold Reservoir collects water from the Mount Lofty Ranges and is supplemented with water pumped from the River Murray, as are most of South Australia's reservoirs. Happy 
Leon van der Linden et al., Suitability of a coupled hydrodynamic water quality model to predict changes in water quality from altered meteorological boundary conditions

Valley Reservoir has experienced a range of water quality challenges in the past, with blue-green algae (cyanobacteria) being a problem in recent decades. The use of artificial destratification (mixing) and algaecides are used for management in the reservoir, while granular activated carbon used in the water treatment process to reduce metabolite concentrations to acceptable levels. As HVR is supplied with water from an unprotected catchment (i.e. containing various farming activities and human habitation), vigilance against pathogens is required and loads of nutrients are greater than is generally desirable. As such, the South Australian Water Corporation has invested heavily in monitoring and research into the processes influencing water quality in this reservoir.

\subsection{Model Description}

ELCOM (Estuary and Lake Computer Model) is a hydrodynamic model that simulates the temporal behavior of stratified water bodies with environmental forcing. The model solves the unsteady, viscous Navier-Stokes equations for incompressible flow using the hydrostatic assumption for pressure. The simulated processes include baroclinic and barotropic responses, rotational effects, tidal forcing, wind stresses, surface thermal forcing, inflows, outflows, and transport of salt, heat and passive scalars (Hodges \& Dallimore, 2007). When coupled with the CAEDYM (Computational Aquatic Ecosystem DYnamics Model) water quality model, ELCOM can be used to simulate three-dimensional transport and interactions of flow physics, biology and chemistry. ELCOM uses the Euler-Lagrange method for advection of momentum with a conjugate-gradient solution for the free-surface height. Passive and active scalars (i.e. tracers, salinity and temperature) are advected using a conservative ULTIMATE QUICKEST discretization (See Hodges \& Dallimore, 2007 and references within for further details).

The Centre for Water Research was previously engaged to apply ELCOM-CAEDYM to Happy Valley Reservoir (Romero et al. 2005). Upon delivery, the model was considered appropriate for the simulation of water movement, contaminant transport, algal growth and biogeochemical cycling (Romero et al. 2005). ELCOM was applied at three resolutions $(25,50$ and $100 \mathrm{~m}$ grid sizes), each suitable for different modelling questions. The hydrodynamic model was validated against temperature sensor data over two periods in 2005 (winter and summer). CAEDYM, the chemical, biological and water quality model, was calibrated over the same periods, with the parameter set derived from applications to other Australian reservoirs and some minor calibration of parameters to suit HVR. The manual calibration focussed on parameters that could not be derived from literature values and included, the density of particulate organic matter, the maximum rate for microbial decomposition of particulate organic phosphorus (nitrogen), the maximum rate of mineralization of dissolved organic phosphorus (nitrogen), the dissolved oxygen $1 / 2$ saturation constant for nitrification, the rate of denitrification and the phosphorus $1 / 2$ saturation constant for algal uptake. Some deficiencies in the calibration of the algal growth components of the model remained. For this work, the model was not further calibrated or modified beyond the work of Romero et al. (2005) and therefore no performance metrics are presented. The lack of extensive calibration to HVR water quality dynamics means the results of the study can be considered to be a general test of the sensitivity of ELCOM-CAEDYM to climate drivers and not an investigation of the likely effects of climate change on water quality in Happy Valley Reservoir.

\subsection{Scenarios for Sensitivity Analysis}

A series of scenarios were defined, synthetic input data files were generated and ELCOM-CAEDYM simulations were run using multi-core parallel processing ( $\mathrm{R}$ Development Core Team 2011). As stratification, algal growth and soluble metal concentrations were of key interest, the summer period simulation was used. The $100 \mathrm{~m}$ grid version of ELCOM was used to minimise the runtime required, as shortcircuiting was not a primary concern of the water quality problems being investigated. The input boundary conditions analysed were selected to represent the 'climate drivers' of precipitation, air temperature and wind speed and are represented by the input files as changes in flow, air and water temperature, and wind speed, respectively (these will be referred to as INFLOW, WIND and TEMP in the text). The synthetic input files were generated by applying a linear multiplier, for INFLOW and WIND, and an increment in the case of TEMP (Table 1). Temperature was modified in this fashion to facilitate comparison to potential temperature change magnitudes. For comparison, -5 and +5 degrees correspond to multipliers of 0.8 and 1.25 , respectively, at 20 degrees Celsius, similar to the average temperature in the reservoir during the simulations. As ELCOM-CAEDYM will fail if changes to the water budget result in violations in the boundary conditions, changes in the inflow and outflow must be balanced, therefore the outflow (consumption at the offtake) was increased by a corresponding amount. The FLOW scenarios could therefore be considered to represent a change in the consumption of water by the water treatment plant (WTP), rather than changes in precipitation, strictly. This may initially seem artificial; however, as HVR is an offline storage and the inflow 
Leon van der Linden et al., Suitability of a coupled hydrodynamic water quality model to predict changes in water quality from altered meteorological boundary conditions

to the reservoir is fully regulated by a flume at Clarendon Weir, it can be interpreted as representing changes in demand, especially as a summer period was considered.

Table 1. Boundary condition modifications applied in the sensitivity analysis.

\begin{tabular}{ccc}
\hline $\begin{array}{c}\text { Temperature } \\
\text { (TEMP) } \\
\text { [increment] }\end{array}$ & $\begin{array}{c}\text { Precipitation } \\
\text { (FLOW) } \\
\text { [multiplier] }\end{array}$ & $\begin{array}{c}\text { Wind Speed } \\
\text { (WIND) } \\
\text { [multiplier] }\end{array}$ \\
\hline-5.0 & 0.50 & 0.50 \\
-2.0 & 0.75 & 0.75 \\
-1.0 & 0.90 & 0.90 \\
-0.5 & 0.95 & 0.95 \\
0.5 & 1.05 & 1.05 \\
1.0 & 1.10 & 1.10 \\
2.0 & 1.25 & 1.25 \\
5.0 & 1.50 & 1.50 \\
\hline
\end{tabular}

Table 2. Summary of average reservoir physical properties for sensitivity analysis simulations of Happy Valley. The factor

\begin{tabular}{lccccc}
\hline & & Temp & Temp & Temp \\
Factor & $\begin{array}{c}\text { Increment } \\
\text { /Multiplier }\end{array}$ & $\begin{array}{c}\mathbf{g}^{\prime} \\
\left(\mathbf{s}^{2}\right)\end{array}$ & $\begin{array}{c}\text { mean } \\
\left({ }^{\circ} \mathbf{C}\right)\end{array}$ & $\begin{array}{c}\left.{ }^{\circ} \mathbf{C}\right) \\
\text { min }\end{array}$ & $\left({ }^{\circ} \mathbf{C}\right)$ \\
\hline Original & - & $\mathbf{0 . 0 5 0 2}$ & $\mathbf{2 0 . 5}$ & $\mathbf{2 1 . 8}$ & $\mathbf{1 6 . 5}$ \\
\hline INFLOW & 0.50 & 0.0481 & 20.9 & 22.2 & 16.6 \\
INFLOW & 0.75 & 0.0490 & 20.8 & 22.0 & 16.6 \\
INFLOW & 0.90 & 0.0496 & 20.6 & 21.9 & 16.5 \\
INFLOW & 0.95 & 0.0498 & 20.6 & 21.9 & 16.5 \\
INFLOW & 1.05 & 0.0503 & 20.5 & 21.8 & 16.5 \\
INFLOW & 1.10 & 0.0505 & 20.5 & 21.8 & 16.6 \\
INFLOW & 1.25 & 0.0510 & 20.3 & 21.7 & 16.6 \\
INFLOW & 1.50 & 0.0513 & 20.2 & 21.5 & 16.6 \\
\hline TEMP & -5.0 & 0.0454 & 17.0 & 18.3 & 13.4 \\
TEMP & -2.0 & 0.0481 & 19.1 & 20.4 & 15.9 \\
TEMP & -1.0 & 0.0490 & 19.8 & 21.1 & 16.2 \\
TEMP & -0.5 & 0.0495 & 20.2 & 21.5 & 16.4 \\
TEMP & +0.5 & 0.0505 & 20.9 & 22.2 & 16.7 \\
TEMP & +1.0 & 0.0511 & 21.3 & 22.5 & 17.0 \\
TEMP & +2.0 & 0.0524 & 22.0 & 23.2 & 17.3 \\
TEMP & +5.0 & 0.0571 & 24.1 & 25.4 & 17.5 \\
\hline WIND & 0.50 & 0.0984 & 22.7 & 25.9 & 17.0 \\
WIND & 0.75 & 0.0681 & 21.5 & 23.4 & 17.0 \\
WIND & 0.90 & 0.0560 & 20.9 & 22.4 & 16.7 \\
WIND & 0.95 & 0.0528 & 20.7 & 22.1 & 16.6 \\
WIND & 1.05 & 0.0474 & 20.4 & 21.6 & 16.6 \\
WIND & 1.10 & 0.0452 & 20.2 & 21.4 & 17.2 \\
WIND & 1.25 & 0.0397 & 19.8 & 20.8 & 17.4 \\
\hline & 1.50 & 0.0334 & 19.3 & 20.1 & 17.3 \\
\hline
\end{tabular}

The scenarios were run using the same initial conditions; a 'spin-up' period of 1 week was excluded from all summary calculations. As potable water production is the focus of the study, water quality (temperature, suspended solids, chlorophyll, iron and manganese) at the reservoir offtake was analysed, along with 'whole of reservoir' characteristics, such as water temperature and an index of the degree of stratification of the water column $\left(g^{\prime}\right)$. Changes in water quality were evaluated as changes in the mean concentration, the maximum concentration and the period of the simulation that the concentration was above a threshold value (green algal and cyanobacterial chlorophyll only, 1 and $10 \mu \mathrm{g} / \mathrm{L}$, respectively). In order to facilitate the interpretation of the phytoplankton dynamics, summaries of the state variables governing the growth of the two species modelled were calculated as means of the time series values.

\section{RESULTS}

\subsection{Lake physical characteristics}

The (modelled) physical properties of the lake were altered by the changes in boundary conditions. The degree of stratification, as indicated by average $g^{\prime}$, was altered in all scenarios; changes in wind speed had a strong negative effect on lake stratification (Table 2). Increasing air and inflowing water temperature resulted in increased reservoir stratification, as did increased flow. Water temperature in the reservoir was not strongly influenced by the INFLOW scenarios, however the WIND and TEMP scenarios had strong effects on the mean of the average, minimum and maximum water temperatures observed over the simulations (Table 2). Only small impacts on reservoir volume and level were observed (not shown). 
Leon van der Linden et al., Suitability of a coupled hydrodynamic water quality model to predict changes in water quality from altered meteorological boundary conditions

\subsection{Water quality parameters}

An increase in average modelled cyanobacterial chlorophyll was observed with elevated temperature (Figure 1A). The average concentration of reduced soluble iron (FeII) also increased with temperature while soluble manganese was less responsive (Figure 1). Sensitivity responses were close to linear near the origin $( \pm 10 \%)$, but some became more non-linear at the extremes of the scenarios investigated. Exceedance of the threshold selected for cyanobacterial chlorophyll increased approximately linearly with increasing temperature above that of the original scenario, but had little effect below that level (data not shown). The FLOW scenarios had a consistently linear influence on reservoir water quality; increasing average concentrations of chlorophyte and cyanobacterial chlorophyll, MnII and FeII were observed in simulations with reduced flow; only the average concentration of suspended solids (SSOL1) decreased with decreasing flow (Figure 1B). Changes in maximum modelled values behaved similarly as did duration of exceedance for the chlorophyll variables (not shown).

The relationship between WIND and algal growth was obviously non-linear with large increases in the average concentrations of both algal groups with decreasing wind speed (Figure 1C). Cyanobacteria were especially favoured by low wind speeds. Reduction of wind speed from $90 \%$ to $75 \%$ of today's averages resulted in a large increase in the duration of exceedance by cyanobacteria (not shown). The simulated phytoplankton production rates were low $\left(\sim 0.1 \mathrm{day}^{-1}\right)$ compared to what they can potentially be $\left(\sim 0.3-0.5\right.$ day $\left.^{-1}\right)$ and probably are in HVR. This was also noted by Romero et al. (2005). The simulated whole lake averages of respiration exceeded that of production in cyanobacteria, indicating that they were limited to growing in a limited volume of the lake where sufficient light was available. Elevated temperatures increased cyanobacterial production rates but these increased production rates were kept in check by elevated respiration. There was

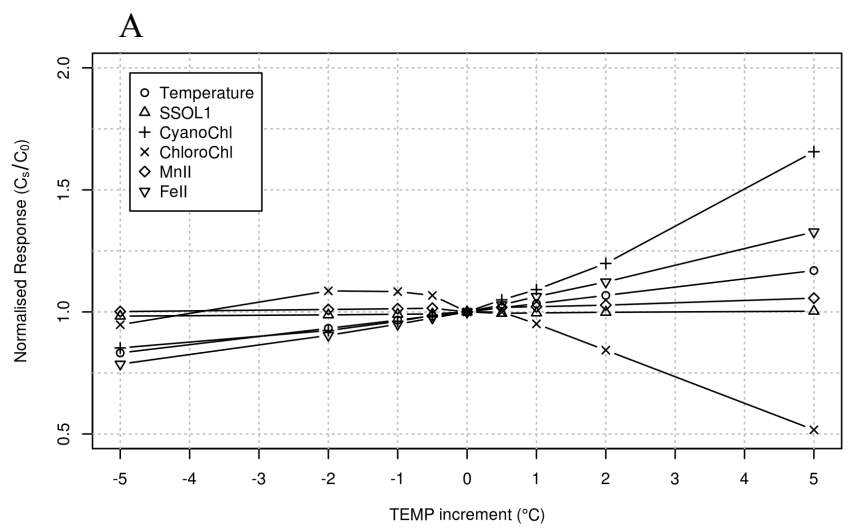

B
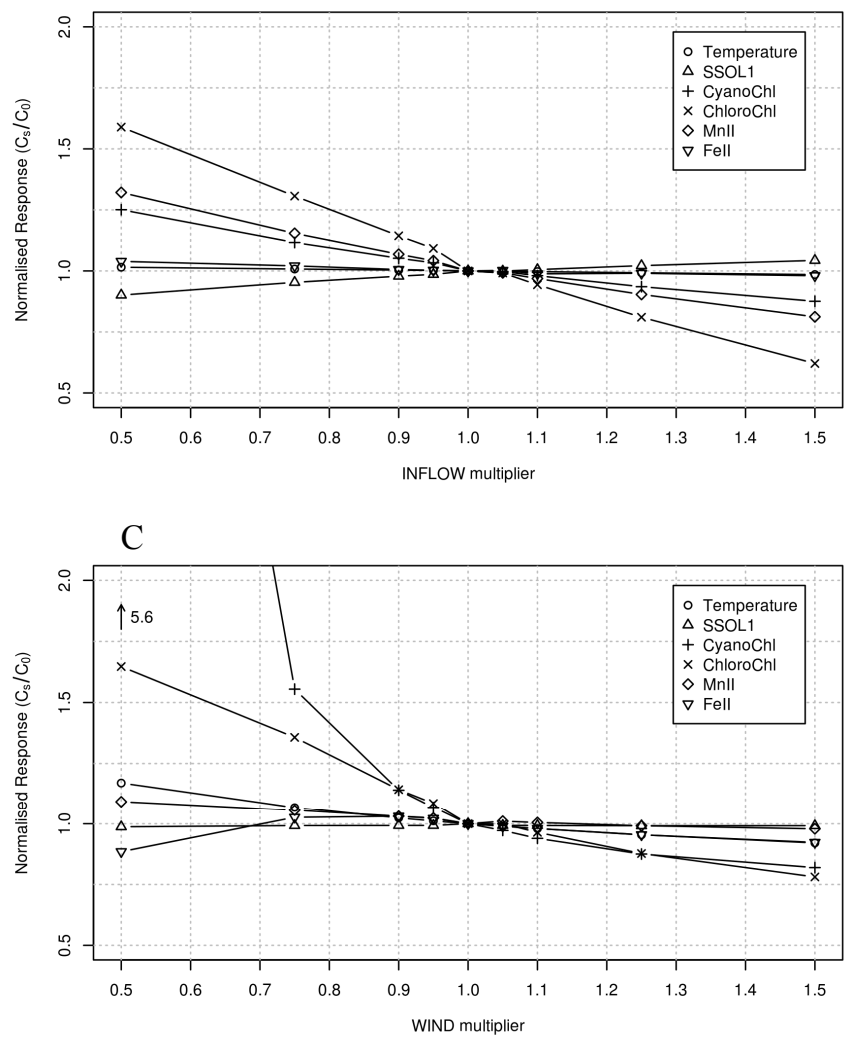

Figure 1. Change in mean modeled water quality values over the summer period in the different sensitivity analysis scenarios where temperature (A), rate of inflow and outflow (B) or wind speed (C) were incrementally changed. The water quality variables presented were water temperature (Temperature), fine suspended solids (SSOL1), cyanobacterial chlorophyll concentration (CyanoChl), green algal chlorophyll concentration (ChloroChl), reduced manganese (MnII) and ferrous iron (FeII) very little change in the nutrient $(\mathrm{N} \& \mathrm{P})$ limitation of phytoplankton, even under the INFLOW scenarios; simulated phytoplankton growth was more limited by light availability (Table 3 ). 
Leon van der Linden et al., Suitability of a coupled hydrodynamic water quality model to predict changes in water quality from altered meteorological boundary conditions

Table 3. Mean cyanobacterial growth characteristics in ELCOM-CAEDYM simulations. The limitation values indicate the degree of growth limitation from 0 to 1 where 1 is unlimited and 0 is completely limited (no growth).

\begin{tabular}{lccccc} 
Scenario & $\begin{array}{c}\text { Production } \\
\left(\mathbf{d a y}^{-1}\right)\end{array}$ & $\begin{array}{c}\text { Respiration } \\
\left(\mathbf{d a y}^{-1}\right)\end{array}$ & Light & Phosphorus & Nitrogen \\
\hline Original & $\mathbf{0 . 0 8 0}$ & $\mathbf{0 . 0 9 3}$ & $\mathbf{0 . 0 9 9}$ & $\mathbf{0 . 9 1 5}$ & $\mathbf{0 . 8 9 0}$ \\
\hline INFLOW by 0.5 & 0.079 & 0.096 & 0.095 & 0.916 & 0.883 \\
INFLOW by 1.5 & 0.081 & 0.091 & 0.102 & 0.916 & 0.890 \\
\hline TEMP by -5 & 0.061 & 0.076 & 0.101 & 0.917 & 0.890 \\
TEMP by +5 & 0.108 & 0.115 & 0.106 & 0.909 & 0.884 \\
\hline WIND by 0.5 & 0.083 & 0.106 & 0.086 & 0.923 & 0.899 \\
WIND by 1.5 & 0.075 & 0.087 & 0.103 & 0.917 & 0.889 \\
\hline
\end{tabular}

\section{DISCUSSION}

These scenarios demonstrate that ELCOM-CAEDYM is sensitive to changes in environmental drivers that are expected to change under future climate. The model tested was not heavily calibrated and therefore the results are able to be generalised. This model would be a suitable component of an integrated modelling approach to evaluate the impacts of climate change on reservoir water quality. The observed sensitivities are consistent with qualitative expectations on the basis of contemporary understanding of reservoir processes. Other authors have observed model sensitivities resulting in increases in the proportion of cyanobacteria by 1 - 7.8\% per $1{ }^{\circ} \mathrm{C}$ increase in temperature (Elliott et al. 2006; Elliott 2012); however, these studies were conducted in a cooler climate (UK). Important interactions with nutrient availability exist (Mooij et al. 2007) but this was not investigated here. As an independent factor, nutrient addition (sensu INFLOW scenarios) did not have a large effect on the phytoplankton dynamics. The model tested in this study employed a relatively simple representation of phytoplankton community dynamics; only two main functional groups were represented. Furthermore some physiological mechanisms that facilitate cyanobacterial dominance, despite being available in CAEDYM, were not used in the model application of Romero et al. (2005). Greater sensitivity and/or more non-linearity may be expected if these mechanisms (e.g. buoyancy regulation) were implemented.

The environmental drivers that were manipulated in the scenarios were not investigated factorially, however they are not completely independent; changes in mean and maximum water temperature occurred in the INFLOW and WIND scenarios. This complicates the interpretation of model outputs without extensive comparison of individual simulations; an effort not warranted by the goals of this study. The scenarios were arbitrarily selected to quickly develop a picture of the sensitivity of the model to changed boundary conditions. As such, the important environmental drivers of dilution and nutrient loading are confounded in the multiplication of inflow volumes. Inflow scenarios assumed the same constituent concentrations and therefore the higher flow scenarios had higher nutrient loads. However as chlorophyll concentrations decreased as flow increased, it is apparent that dilution was a more important driver of algal biomass than nutrient load and availability. Despite this, the prediction that phytoplankton growth is rarely limited by nutrient availability may suggest that reducing the external load may be an option for reducing algal growth. The internal load was not investigated as part of this study but given the short water retention time of the reservoir, it is probably of minor importance, compared to the external load. The reduction of nutrient availability represents a potential strategy for adaptation to climate change and the likely negative effects on water quality resulting from increased cyanobacterial growth. Water quality models, such as ELCOMCAEDYM, have an important role to play in determining the potential benefit of a nutrient reduction program.

\section{CONCLUSIONS}

This study demonstrated that ELCOM-CAEDYM is sensitive to climate drivers and suitable for use in climate impact studies. It further highlighted the important factors in determining phytoplankton growth and that any changes in inflowing water quality will be of major importance to the reservoir water quality dynamics. 
Leon van der Linden et al., Suitability of a coupled hydrodynamic water quality model to predict changes in water quality from altered meteorological boundary conditions

\section{REFERENCES}

Arheimer, B., Andréasson, J., Fogelberg, S., Johnsson, H., Pers, C.B. \& Persson, K. (2005) Climate change impact on water quality: model results from southern Sweden. Ambio, 34, 559-66.

Brookes, J., Burch, M., Hipsey, M.R., Linden, L., Antenucci, J., Steffensen, D., Hobson, P., Thorne, O., Lewis, D., Rinck-Pfeiffer, S., Kaeding, U., Rasmussen, P. \& Ramussen, P. (2008) A Practical Guide to Reservoir Management. Cooperative Research Centre for Water Quality and Treatment, Adelaide, Australia.

Charles, S.P., Heneker, T. \& Bates, B.C. (2008) Stochastically downscaled rainfall projections and modelled hydrological response for the Mount Lofty Ranges, South Australia. Water Down Under (eds M. Lambert, T. Daniell \& M. Leonard), pp. 428-438. Adelaide Australia.

CSIRO. (2007) Climate Change in Australia. CSIRO, Canberra, Australia.

CSIRO. (2012) State of the Climate 2012. CSIRO and Bureau of Meteorology.

Delpla, I., Jung, A.-V., Baures, E., Clement, M. \& Thomas, O. (2009) Impacts of climate change on surface water quality in relation to drinking water production. Environment International, 35, 1225-1233.

Elliott, J.A. (2012) Is the future blue-green? A review of the current model predictions of how climate change could affect pelagic freshwater cyanobacteria. Water Research, 46, 1364-1371.

Elliott, J.A., Jones, I.D. \& Thackeray, S.J. (2006) Testing the sensitivity of phytoplankton communities to changes in water temperature and nutrient load, in a temperate lake. Hydrobiologia, 559, 401-411.

Green, G., Gibbs, M. \& Wood, C. (2011) Impacts of Climate Change on Water Resources, Phase 3 Volume 1: Northern and Yorke Natural Resources Management Region DFW Technical Report 2011/03.

Heneker, T. \& Cresswell, D. (2010) Potential Impact on Water Resource Availability in the Mount Lofty Ranges Due to Climate Change. Adelaide.

Hipsey, M.R., Romero, J.R., Antenucci, J.P. \& Hamilton, D.P. (2006) Computational Aquatic Ecosystem Dynamics Model CAEDYM V2.3 User Manual. Centre for Water Research, University of Western Australia.

Hodges, B. \& Dallimore, C. (2007) Estuary, Lake and Coastal Ocean Model: ELCOM V2 . 2 User Manual. Centre for Water Research, University of Western Australia.

Mimikou, M.A., Baltas, E., Varanou, E. \& Pantazis, K. (2000) Regional impacts of climate change on water resources quantity and quality indicators. Journal of Hydrology, 234, 95-109.

Mooij, W.M., Janse, J.H., Senerpont Domis, L.N., Hülsmann, S. \& Ibelings, B.W. (2007) Predicting the effect of climate change on temperate shallow lakes with the ecosystem model PCLake. Hydrobiologia, 584, 443-454.

R Development Core Team. (2011) R: A Language and Environment for Statistical Computing. R Foundation for Statistical Computing, Vienna, Austria.

Romero, J., Antenucci, J. \& Okley, P. (2005) Happy Valley Reservoir Modelling Study - Final Report. Centre for Water Research, University of Western Australia.

Saloranta, T., Forsius, M., Järvinen, M. \& Arvola, L. (2009) Impacts of projected climate change on the thermodynamics of a shallow and a deep lake in Finland: model simulations and Bayesian uncertainty analysis. Hydrology Research, 40, 234.

Thorne, O.M. \& Fenner, R.A. (2008) Modelling the impacts of climate change on a water treatment plant in South Australia. Water Science and Technology: Water Supply, 8, 305.

Whitehead, P.G., Wilby, R.L., Battarbee, R.W., Kernan, M. \& Wade, A.J. (2009) A review of the potential impacts of climate change on surface water quality. Hydrological Sciences Journal - Journal des Sciences Hydrologiques, 54, 101-123. 